\title{
Enhancement of power quality using microprocessor based shunt active power filter for unbalanced load
}

\author{
Madhu B. R. ${ }^{1}$, Dinesh M. N. ${ }^{2}$, Tsewang Thinlas ${ }^{3}$, Deril Menezes ${ }^{4}$ \\ ${ }^{1}$ Department of Electrical and Electronics Engineering, Jain University, India \\ ${ }^{2,3,4}$ Department of Electrical and Electronics Engineering, Rashtreeya Vidyalaya College of Engineering, India
}

\begin{tabular}{l}
\hline Article Info \\
\hline Article history: \\
Received May 14, 2019 \\
Revised Feb 1, 2020 \\
Accepted Feb 9, 2020 \\
\hline Keywords: \\
Instantaneous reactive power \\
theory \\
Shunt active power filter \\
(SAPF) \\
STM32F303RET6 \\
microcontroller \\
Three phase three leg IGBT \\
inverter
\end{tabular}

\begin{abstract}
Power quality is the most significant factor of power sector. The end user equipment such as induction motor, inverters, rectifiers inject harmonics into power system that influences the quality of power delivered. The presence of harmonics forces the use of instantaneous reactive power theory to calculate instantaneous power that helps in finding the compensating currents to eliminate harmonics. The control action required by active filter is accomplished by STM32F303RET6 microcontroller. Single phase induction motor is used as a dynamic nonlinear load in one of the three phases and resistive loads on the other two phases. TRIAC based RC triggering circuit was used to control the single phase induction motor. This paper presents the simulation and hardware implementation of shunt active power filter for 3 phase 4 wire unbalanced system. The hardware results show that THD in the source side has been reduced from $50.7 \%$ to $9.6 \%$ by implementing the SAPF.
\end{abstract}

Copyright () 2020 Institute of Advanced Engineering and Science. All rights reserved.

\section{Corresponding Author:}

Madhu B. R.,

Department of Electrical Engineering,

Jain University,

Bengaluru, 560001-India.

Email:madhu3rao@gmail.com

\section{INTRODUCTION}

The nature of energy conveyed to the end client is influenced by different factors such as voltage and frequency variations, faults, blackouts and so forth. These power quality issues reduce the life time and productivity of the electrical equipment [1-4]. A large portion of the loads are likewise semiconductor based. However the loads containing semiconductor are nonlinear in nature and draws non-sinusoidal current from the supply [5]. Furthermore the semiconductor devices are utilized for conversion of power from AC to DC or vice versa. This conversion of power largely contains switching operations which is the main reason they draw non sinusoidal current. In order to keep up the standard of power transferred, the harmonics should be reduced. Along these lines, an apparatus named filter is utilized that fills this need. There are a few filter topologies presently being used like passive, active and hybrid [6].

Passive filter are prone to resonance. To improve the performance of passive filter and additionally the power system, it must be combined with active filter to form hybrid power filter. Various control strategies are studied and analyzed in literature. The objective of any control strategy is to develop an active filter that injects a current that is out of phase with the harmonics present so as to compensate them. Instantaneous reactive power theory presents a tool to measure the power of any arbitrary wave, hence this can be very powerful tool to measure the power content of harmonics. Hysteresis controller is a powerful strategy to inject calculated reference current [7-9]. It discusses the various control algorithms to calculate the reference current. The various control techniques such as ANN, artificial intelligence, predictive control on active filter to reduce harmonics due to nonlinear loads [10-13]. 
There are various topologies in active power filter such as series and shunt active power filter. They vary with respect to DC bus voltage, rating of the inverter required and cost [14]. DC bus voltage is higher in case of pure active filters. DC bus capacitance value has a significant effect on the performance of active power filters [15].

These days several industries are making use of variable frequency drives for control of induction motor. These variable frequency drives produce different harmonics that results in malfunctioning of the motor, electromagnetic interference introduction, faulty measurement of measuring devices. Harmonic distortions mostly happen where loads draw non-sinusoidal current from the network. It is mostly present in a system where AC is transformed into DC [16]. The study of the effect of harmonics on the performance of induction motors has been done in $[17,18]$. Around, $60 \%$ of loads around the globe are motor loads. More than $90 \%$ of these are used up by 3 phase induction motors with a huge utility factor between 0.7 and 0.9 a day. Pulse Width Modulation (PWM) technique is proven to be an effective way of regulating speed of an induction motor [19]. Use of single-phase induction motor and resistive loads on different phases makes the system unbalanced. Hence, study of 3 phase 4 wire unbalanced system becomes crucial [20-22].

Since most of the research work has been carried out on power quality issues due to static nonlinear load, and not many have studied the performance on dynamic nonlinear load for three-phase four-wire unbalanced system and its effect on power quality issues. Since many of the domestic, industrial and commercial loads are dynamic nonlinear loads like motor drives, it becomes essential to study their effect on power quality due to harmonic production in the system and to reduce their effects by adopting a proper harmonic mitigation method.

\section{INSTANTANEOUS REACTIVE POWER THEORY FOR THREE PHASE FOUR WIRE SYSTEM}

Figure 1 depicts the block diagram of instantaneous reactive power theory for calculation of compensating currents at PCC [23-25]. Using Clarke's transformation the 3 phase voltages $\left(\mathrm{v}_{\mathrm{a}}, \mathrm{v}_{\mathrm{b}}, \mathrm{v}_{\mathrm{c}}\right)$ and load currents $\left(i_{a}, i_{b}, i_{c}\right)$ are converted into single phase i.e $v_{\alpha}, v_{\beta}, v_{0}$ and $i_{\alpha}, i_{\beta}, i_{0}$. Using this the instantaneous power calculation block calculates the elements of active and reactive power of the non-linear load that need to be remunerated by the filter.

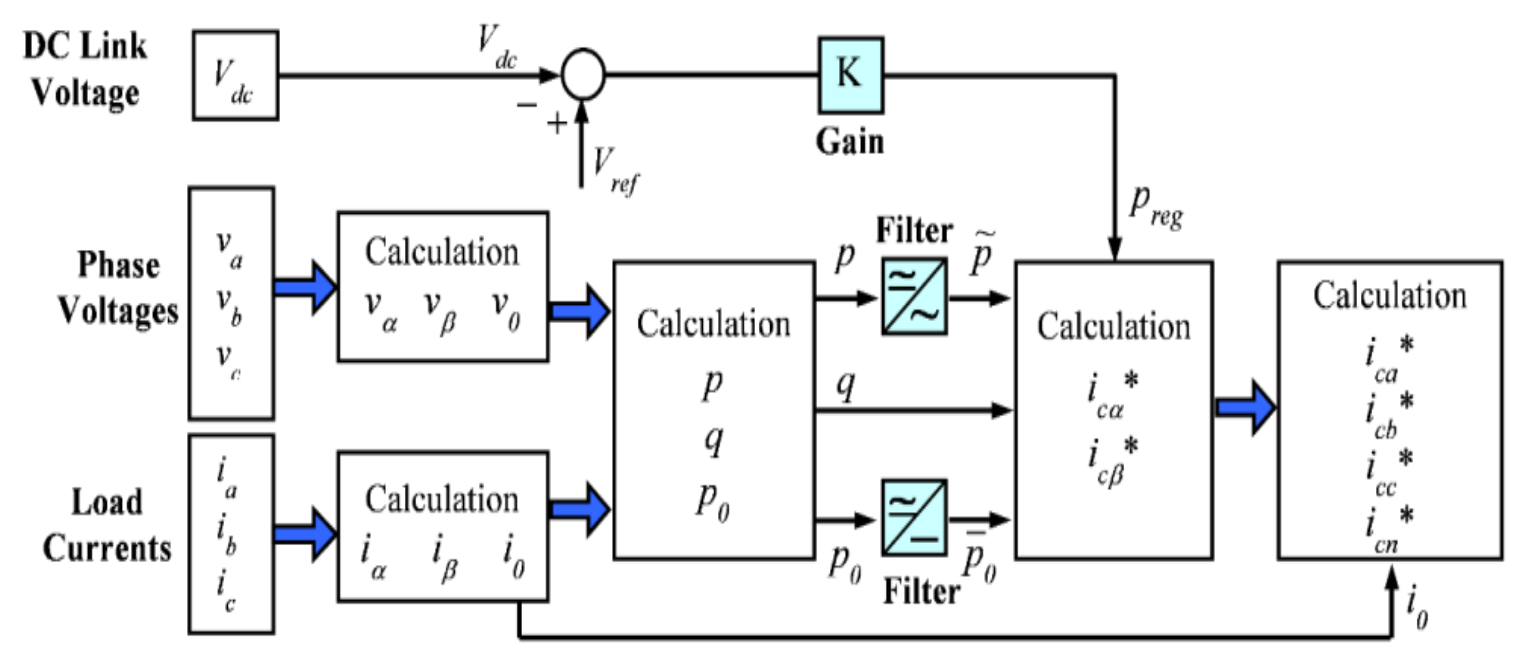

Figure 1. Block diagram of instantaneous reactive power [19]

The dc-voltage regulation block consisting of PI controller determines the additional quantity of power Preg that causes an extra flow of energy to the DC link to maintain its voltage around the reference voltage $\mathrm{V}_{\text {ref. }}$. This Preg is added to the compensating active power Pc along with the compensating reactive power $\mathrm{Q}_{c}$, are passed to calculate reference current. It determines the instantaneous countervailing reference current from the unwanted powers. Then by applying inverse Clarke's transformation the single phase is converted into three phase. Figure 2 indicates the simulation model of instantaneous reactive power theory in MATLAB Simulink platform. 


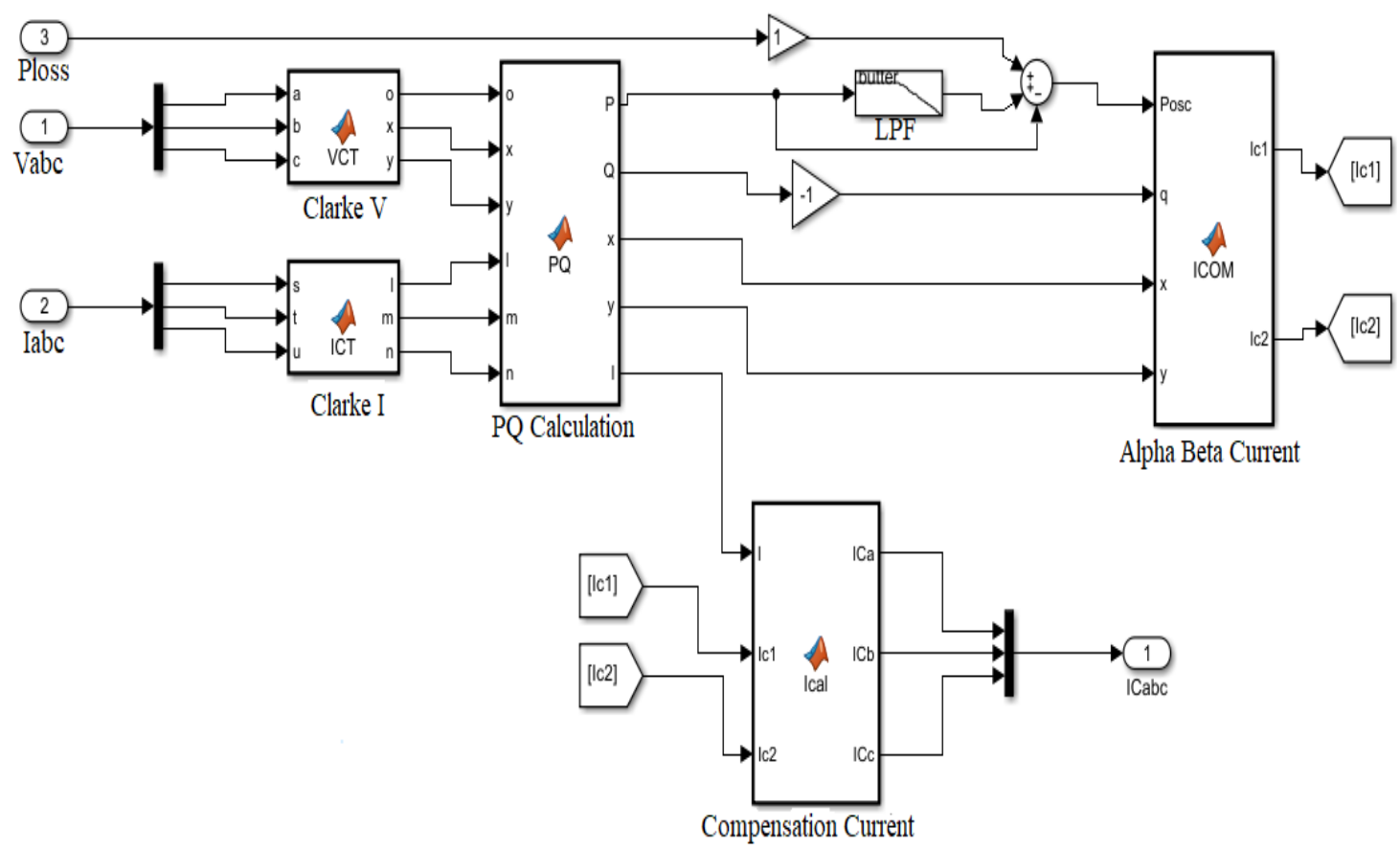

Figure 2. Simulink model of instantaneous reactive power theory for shunt current compensation in SAPF

\section{THREE PHASE FOUR WIRE SHUNT ACTIVE POWER FILTER CONTROLLER}

Figure 3 shows the block diagram of a 3 phase 4 wire shunt active power filter for harmonic current compensation. It has power circuit and compensation circuit. Single phase induction motor and two resistances in each phase are connected to make a load unbalanced. Voltage controller in phase A is used in series with induction motor that injects harmonics in the line. Voltage controller is a TRIAC based, that uses $\mathrm{RC}$ triggering circuit to generate gating pulses. Figure 4 shows the MATLAB Simulink model of complete SAPF. It contains 3 phase source, measurement unit, load and compensating circuit.

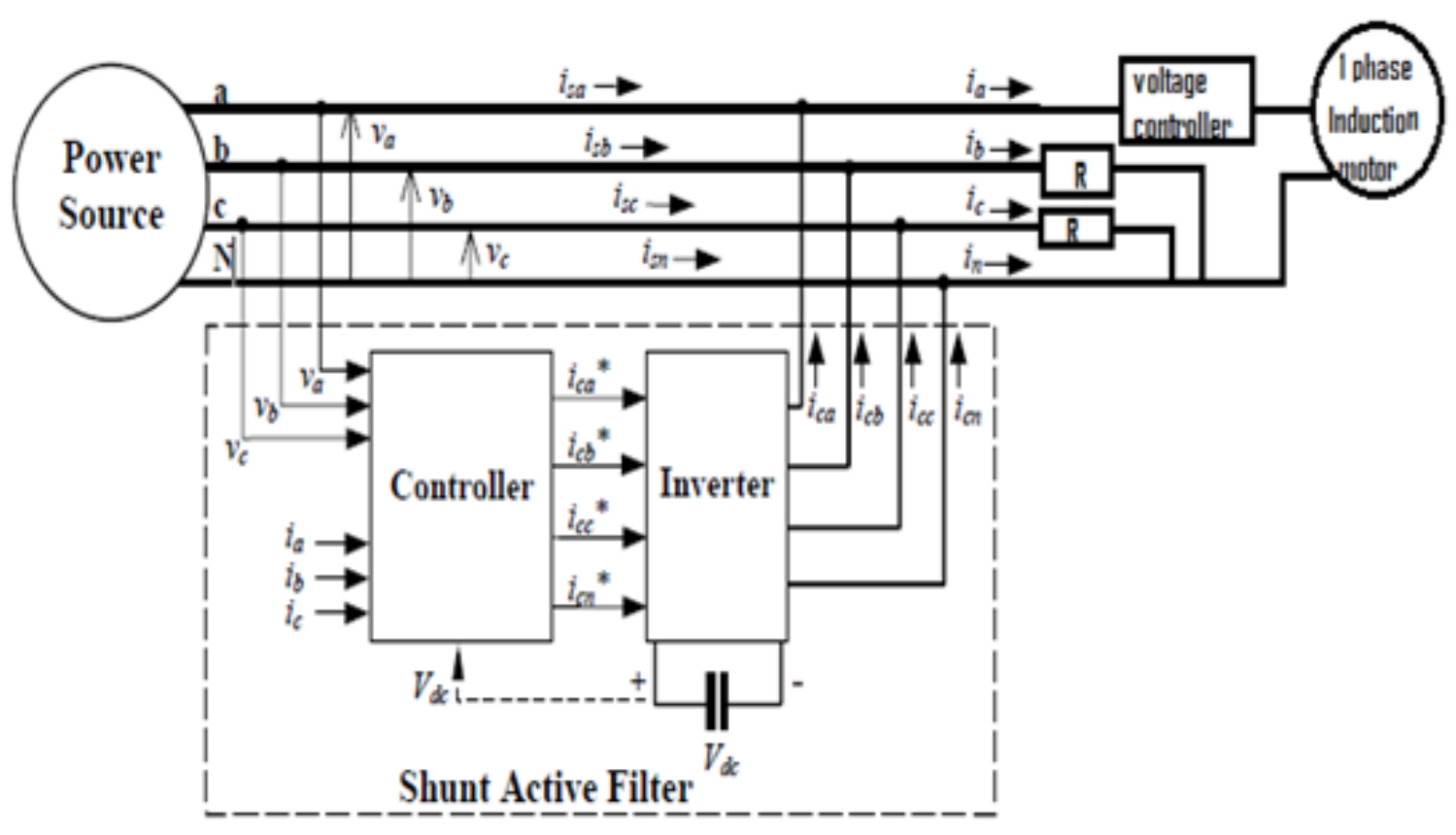

Figure 3. Block diagram of 3-phase 4-wire shunt active power filter 


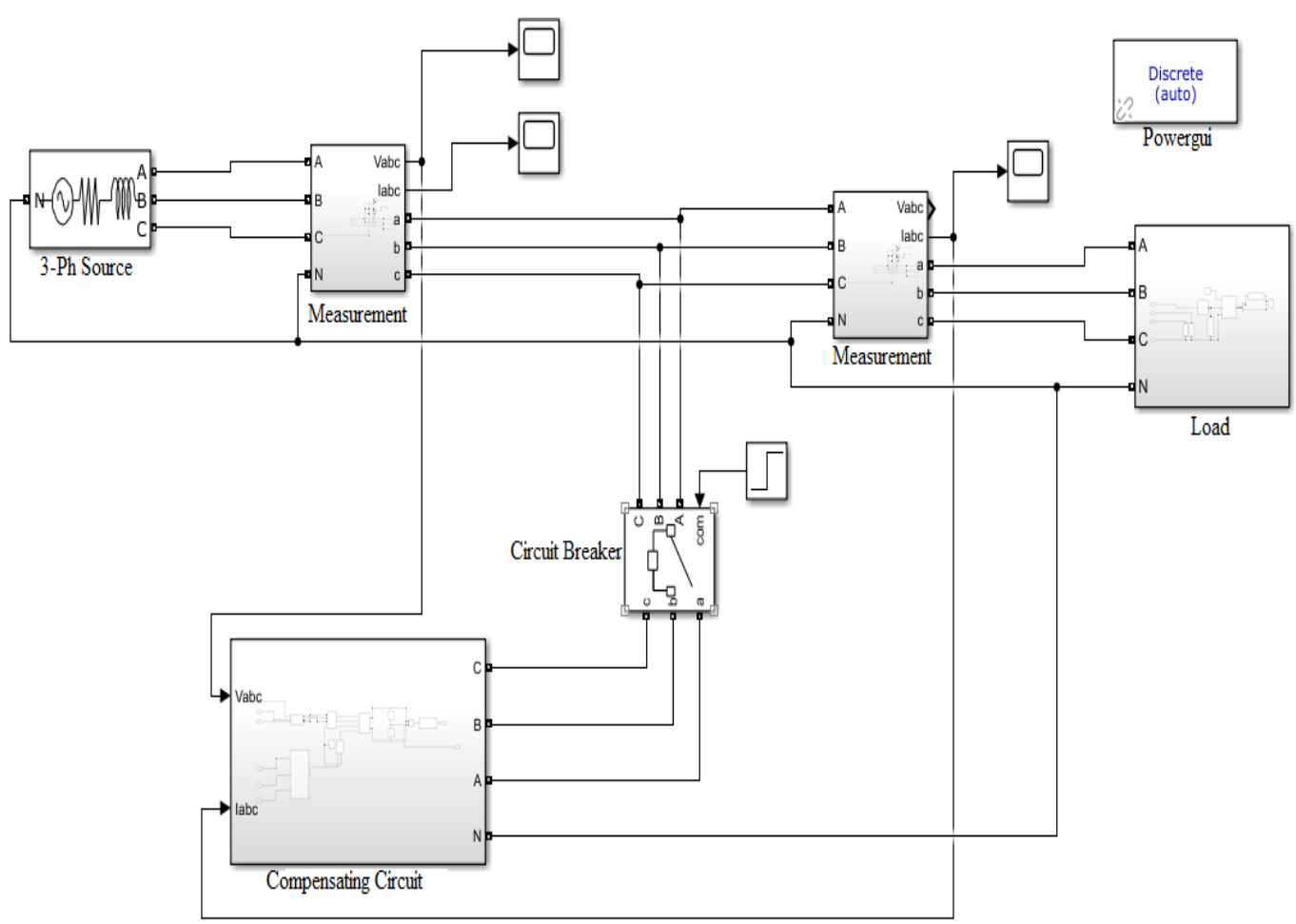

Figure 4. Simulink model of 3 phase 4 wire SAPF

\section{THREE PHASE UNBALANCED LOADS}

Single phase $0.5 \mathrm{HP}$ induction motor with $1500 \mathrm{rpm}$ is connected in phase, and resistive load (100 ohms) in other 2 phases as shown in Figure 5. The simulation model is simulated in the discrete mode. The electrical machines are nonlinear loads simulated as current sources. Therefore, these elements ca not be attached to an inductive network unless and until a resistive or capacitive component is connected across the machine terminals. So, a parasitic resistive load is connected across the motor to avoid numerical oscillations. The size of the parasitic load depends upon the size of the motor. The motor is connected in series with TRIAC converter to generate harmonics.

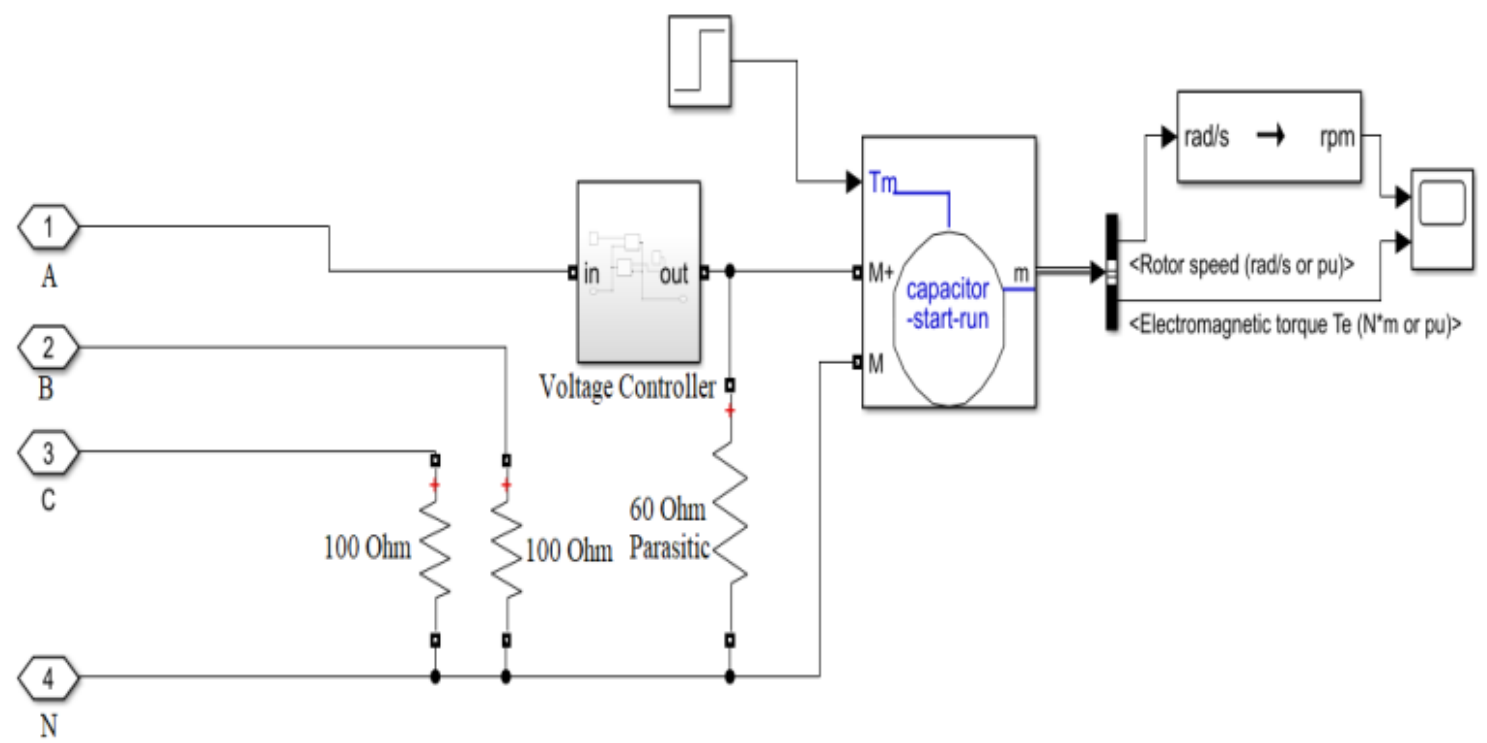

Figure 5. TRIAC voltage controller with motor and resistive load 


\section{SIMULATION RESULTS}

\subsection{Waveform and \%THD on source side without SAPF}

The Figure 6 shows the voltage and current waveform without compensation. Figure 7 represents the percentage of current THD is $14.75 \%$.

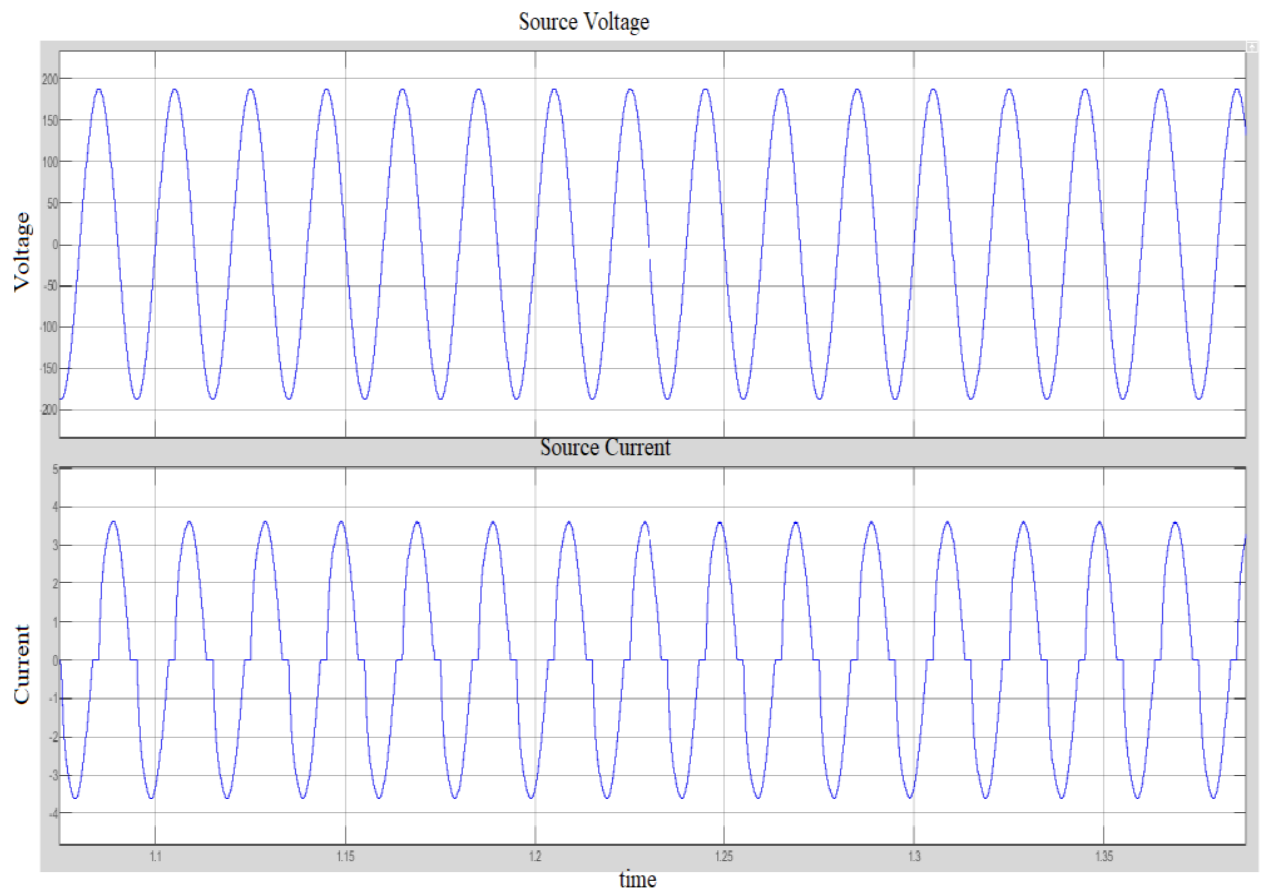

Figure 6. Voltage and current waveform

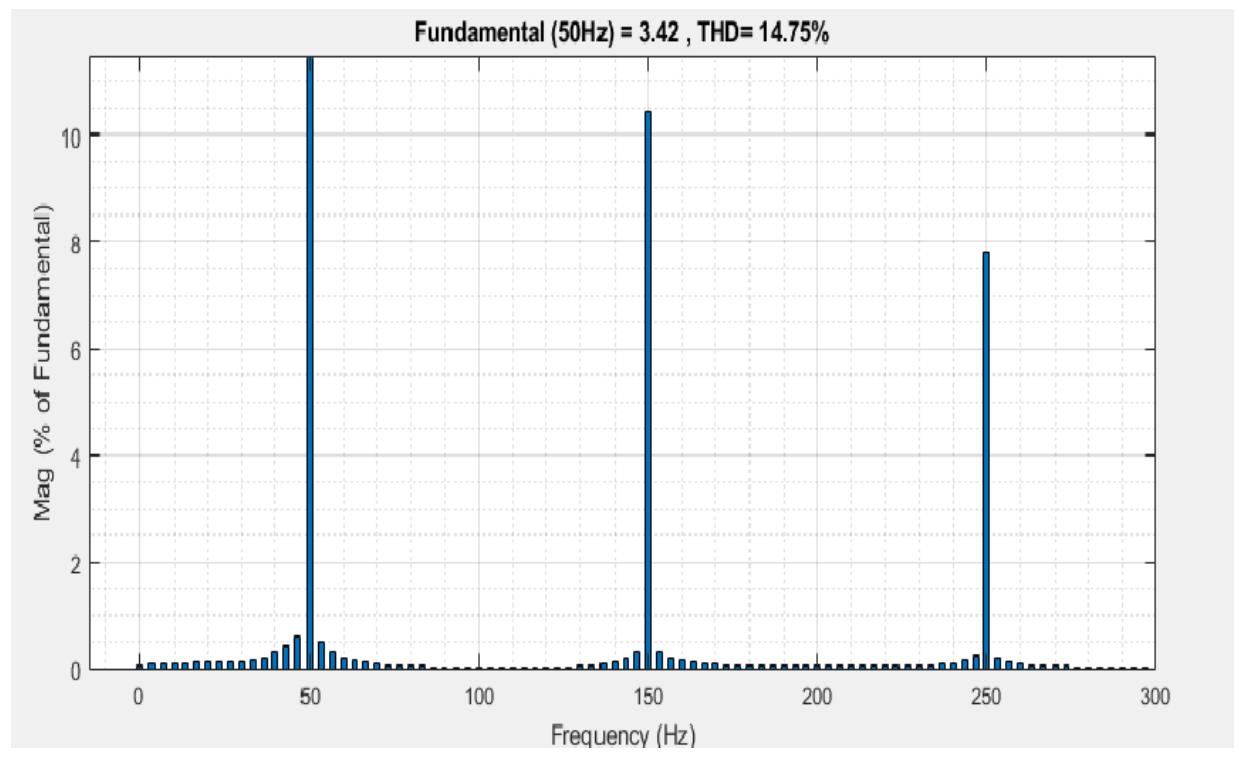

Figure 7. \% THD in source current

\subsection{Waveform and \%THD on source side with SAPF}

The Figure 8 shows the voltage and current waveform with SAPF. Figure 9 represents the percentage of current THD is $3.72 \%$. The FFT analysis of load current with $50 \mathrm{~Hz}$ as fundamental frequency reveals that THD of the current on source side without filter is $14.75 \%$. The THD of the current on source side with filter is reduced to $3.72 \%$. 


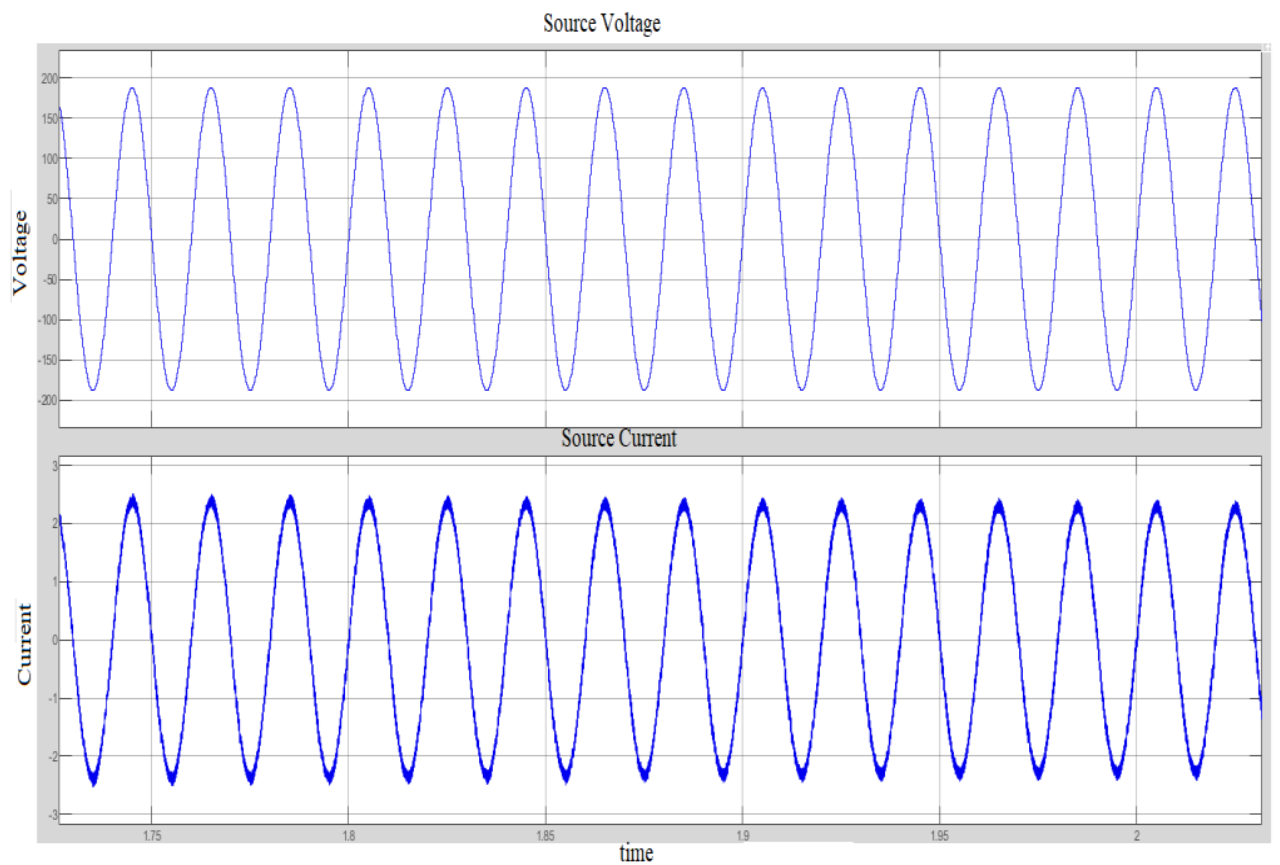

Figure 8. Voltage and current waveform

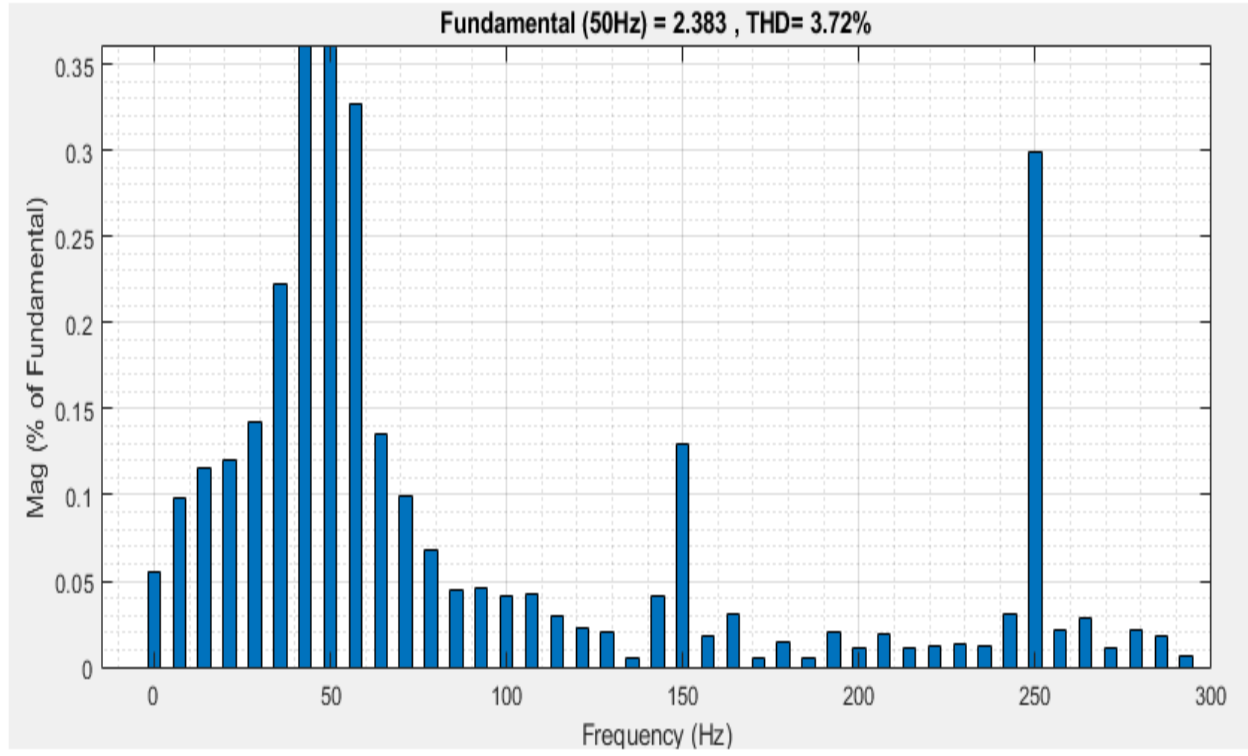

Figure 9. \% THD is source current

\section{HARDWARE IMPLEMENTATION of SAPF}

The Table 1 indicates the rating of SAPF for 3-phase 4-wire unbalanced load. A 230V, 3 phase AC supply is given through a transformer to the dynamic load (i.e. single phase induction motor) at one phase and also resistors in other two phases. The system comprises of 3 phase 4 wire system in unbalanced condition as shown in Figure 10, zero sequence current and voltage also plays a vital role. Current sensor ACS712 is used for current measurement that gives voltage output compatible for microcontroller analogues to current. For Isa, Isb, and Isc represent the current sensor measuring source currents of three phases. Ica, $\mathrm{Icb}$, and Icc represent the current sensor measuring the three phase compensatory currents being injected by three phase inverter into the system. These also form the feedback loop for hysteresis controller. A step-down transformer is utilized to step-down the voltage of 230 volts (RMS) to 24 volts (peak-peak). This voltage 
is then fed to an $\mathrm{AC}$ voltage measuring unit which gives the required DC shift and attenuates the signal measured by STM32F303RET micro controller. The gate driver provides $15 \mathrm{~V}$ output required by the inverter as the PWM signals from micro controller are $3.3 \mathrm{~V}$ signals. The experimental setup of SAPF is depicted in Figure 11.

Table 1. Specifications of SAPF

\begin{tabular}{ll}
\hline Voltage Rating & 230V \\
\hline Load & 3-Phase 4-wire unbalanced loads. \\
& Phase A has 0.5 HP, 1500 RPM \\
& single phase induction motor. \\
& Phase B and C has resistive loads \\
& each of 100 ohms. \\
& Three phase VSI inverter with \\
Active controller & six IGBT's \\
\hline
\end{tabular}

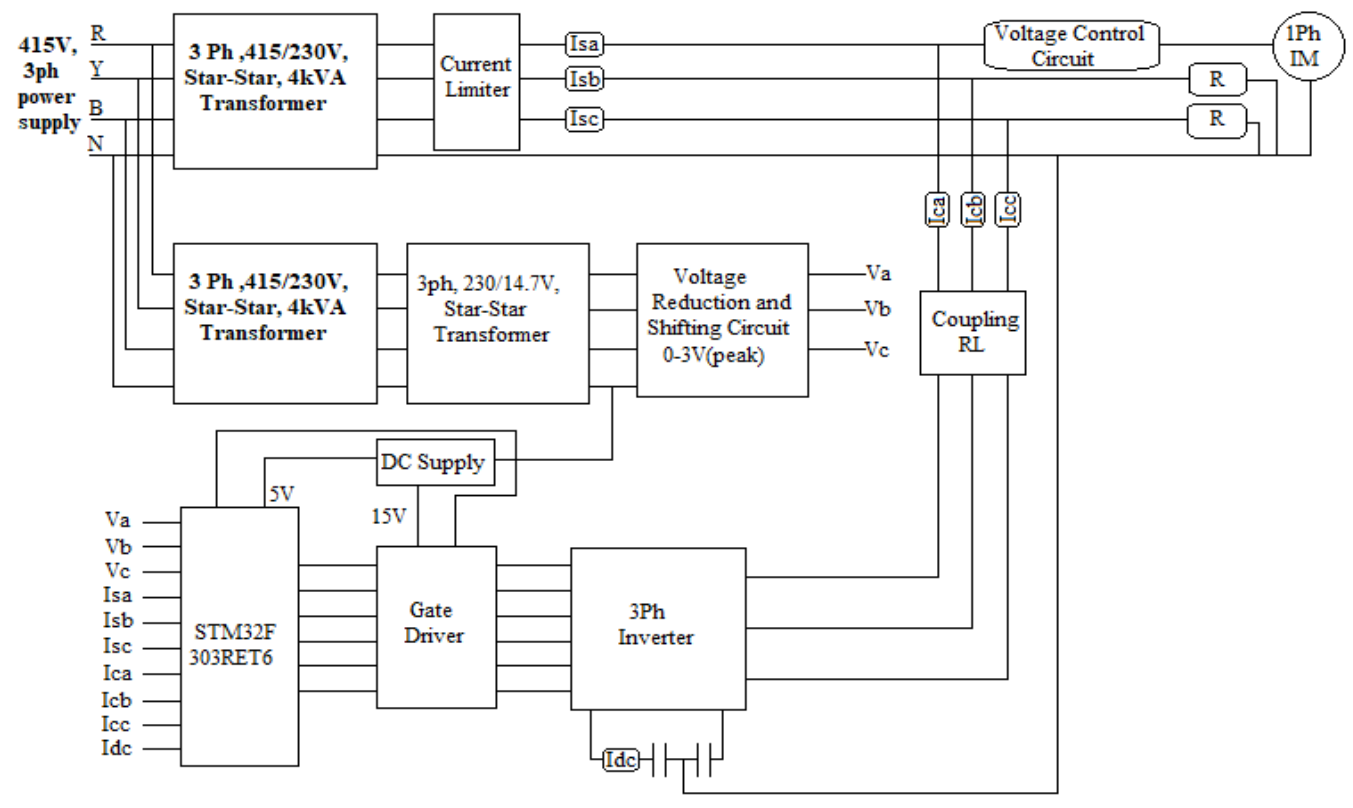

Figure 10. Block diagram for hardware implementation of SAPF

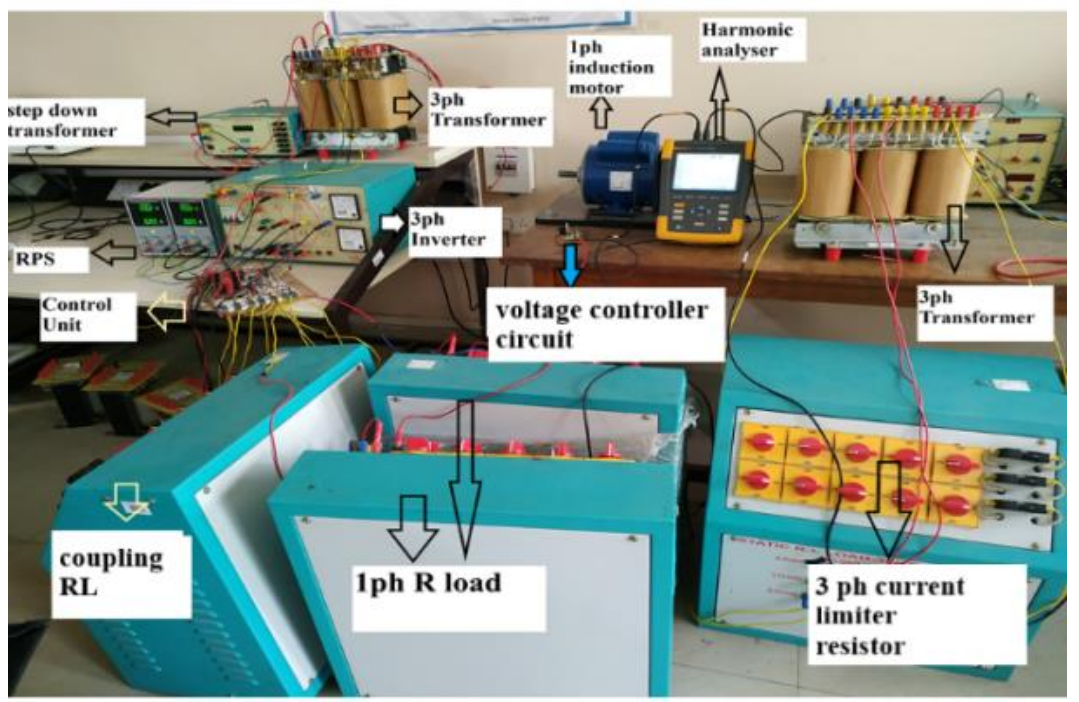

Figure 11. Experimental setup of SAPF 


\section{THREE PHASE THREE LEG IGBT INVERTER RATED 75A/1200V}

The specifications of three phase inverter are indicated in Table 2. Inverter module consists of IGBT switches SKM75GB123D (3 No's), diode bridge rectifier PSD8316, IGBT Gate Drivers SKYPER $32 \mathrm{R}$ and DC Link Capacitors $4700 \mu \mathrm{F}$ (2 No's). The controller in SAPF calculates the reference currents for hysteresis controller that will be injected into power system by three phase IGBT inverter.

Table 2. Specifications of three phase inverter

\begin{tabular}{ll}
\hline Parameter & Rating \\
\hline Output AC Voltage & $415 \mathrm{~V}($ controlled $)$ \\
Switching frequency & $20 \mathrm{KHz}$ \\
Maximum ambient temperature & $400^{\circ} \mathrm{c}$ \\
Control inputs & $5 \mathrm{~V}$ to $15 \mathrm{~V}$ \\
\hline
\end{tabular}

\section{STM32F303RET6 MICROCONTROLLER}

A code is designed based on instantaneous reactive power theory for calculating compensating currents in SAPF and implemented using Keil MDK $\mu$ Vision v.5 embedded platform to program in STM32F303RET6 microcontroller. The following are the steps to implement the IRP algorithm in SAPF for three phase four wire unbalanced dynamic load using microcontroller.

1. Start

2. Iritialize GPIO pins

3. Iritialize DMA to Circular mode and data width to 32 bit

4. Initialize $\mathrm{ADC} 1$ and $\mathrm{ADC} 2$ to dual regular simultaneous mode and set extemal trigger conversion source to be Timer 3

5. Iritialize Timer 3 to up court mode, timer period to 7200

6. Start timer 3

7. Start $\mathrm{ADCs}$ in multimode with DMA

8. Wait for end of sequence of corversion flag to be set

9. IfEOC is set retrieve ac voltages, currents and dc voltage from DMA values

10. Calculate $\alpha, \beta, o$, values for voltages and currents from the data stored in DMA $V_{0}=\sqrt{\frac{2}{3}}\left(\frac{1}{\sqrt{2}} V_{a}+\frac{1}{\sqrt{2}} V_{b}+\frac{1}{\sqrt{2}} V_{c}\right), V_{a}=\sqrt{\frac{2}{3}}\left(V_{a}-\frac{1}{2} V_{b}-\frac{1}{2} V_{c}\right)$ and $V_{\beta}=\sqrt{\frac{2}{3}}\left(\frac{\sqrt{3}}{2} V_{b}-\frac{\sqrt{3}}{2} V_{c}\right)$

Same formulas are also applicable for currents by replacing voltages by currents.

11. Calculate instantaneous power $\mathrm{p}$ and $\mathrm{q}$ using the formula $p=\left(V_{\alpha} * I_{\alpha}\right)+\left(V_{\beta} * I_{\beta}\right)+\left(V_{0} * I 0\right)$ and $q=\left(V_{\alpha} * I_{\beta}\right)-\left(V_{\beta} * I_{\alpha}\right)$

12. Filter out the fundamental components present in the instantaneous active power and add the switching losses to it.

13. Calculate compensation currents in $\alpha, \beta$ coordinates using the below formulae $I_{c 1}=\frac{-1}{\left(V_{\alpha}^{2}+V_{\beta}^{2}\right)} *\left[\left(P_{o s c} * V_{\alpha}\right)+\left(q * V_{\beta}\right)\right]$ and $I_{c 2}=\frac{-1}{\left(V_{\alpha}^{2}+V_{\beta}^{2}\right)} *\left[\left(P_{o s c} * V_{\beta}\right)-\left(q * V_{\alpha}\right)\right]$

14. Calculate the compensation current in abc coordinate using inverse Clark transformation using below formulae and compare it with reference

$$
\begin{aligned}
& I_{c c}=\sqrt{\frac{2}{3}} *\left(\frac{i_{0}}{\sqrt{2}}+I_{c 1}\right), I_{c b}=\sqrt{\frac{2}{3}} *\left[\frac{i_{0}}{\sqrt{2}}-\left(\frac{1}{2} * I_{c 1}\right)+\left(\frac{\sqrt{3}}{2} * I_{c 2}\right)\right] \text { and } \\
& I_{c c}=\sqrt{\frac{2}{3}} *\left[\frac{i_{0}}{\sqrt{2}}-\left(\frac{1}{2} * I_{c 1}\right)-\left(\frac{\sqrt{3}}{2} * I_{c 2}\right)\right]
\end{aligned}
$$

15. If reference current is greater than measured current than set upper switches, else lower switches.

16. Go to step 8 .

\section{HARDWARE RESULTS}

Figure 12 shows that the \% THD of the source side is $50.7 \%$ without compensation for unbalanced dynamic load as measured with harmonic analyser (fluke make). Figure 13 shows that the \%THD of the source side is reduced to $9.5 \%$ from $50.7 \%$ with compensation for unbalanced dynamic load as measured with harmonic analyser. 


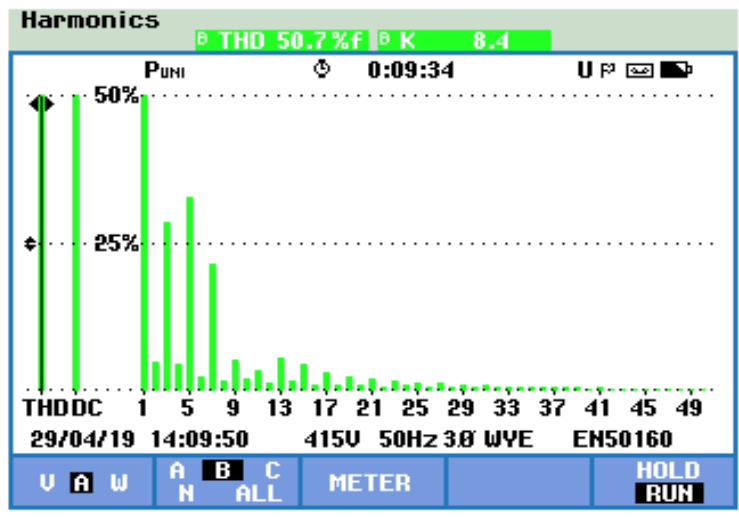

Figure 12.\% THD without compensation

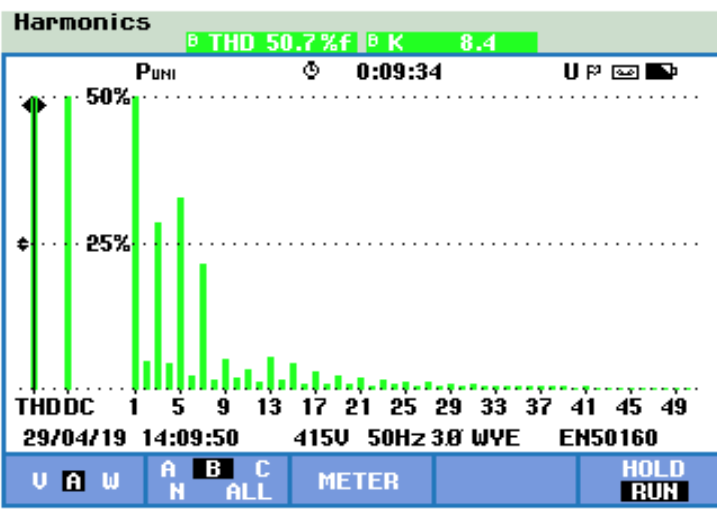

Figure 13. \% THD with compensation

\section{CONCLUSION}

The SAPF works well with dynamic non-linear load and improves the power quality of the power system. Results of simulation evidences that the total THD percentage in the source current is seen to be reduced to $3.72 \%$ from $14.75 \%$ by implementing Shunt APF for a converter controlled single phase induction motor load. Experimental result shows that the total THD content in source current is reduced to $9.6 \%$ from $50.7 \%$ by implementing the Shunt APF for a converter controlled single phase induction motor load. Further the same system can be tested for compensation of harmonics in a system having three phase induction motor.

\section{REFERENCES}

[1] M. J. Ghorbani and H. Mokhtari, "Impact of harmonics on power quality and losses in power distribution systems," International Journal of Electrical and Computer Engineering (IJECE), vol. 5, no. 1, pp. 166- 174, 2015.

[2] V. Kavitha and K. Subramanian, "Investigation of power quality issues and its solution for distributed power system," Int. Conference on Circuits Power and Computing Technologies, pp. 1-6, 2017.

[3] A. Agarwal, S. Kumar, and S. Ali, "A research review of power quality problems in electrical power system," MIT Int. Journal of Electrical and Instrumentation Engineering, vol. 2, no. 2, pp. 88-93, 2012.

[4] D. O. Johnson and K. A. Hassan, "Issues of power quality in electrical systems," Int. Journal of Energy and Power Engineering, vol. 5, no. 4, pp. 148-154, 2016.

[5] L. Cividino, "Power factor, harmonic distortion; cause, effects and considerations," $14^{\text {th }}$ Int. Telecommunications Energy Conference - INTELEC PZ., pp. 505-513, 1992.

[6] F. Z. Peng, "Harmonic sources and filtering approaches," IEEE Industry Application Magazine, vol. 7, no. 4, pp. 18-25, 2001.

[7] Madhu B. R., Dinesh M. N., and Ravitheja B. M., "Design of shunt hybrid active power filter to reduce harmonics on AC side due to non-linear loads," International Journal of Power Electronics and Drive Systems (IJPEDS), vol. 9, no. 4, pp. 1926-1936, 2018.

[8] S. Chourasiya and S. Agrawal, "A review: Control techniques for shunt active power filter for power quality improvement from non-linear loads," Int. Journal of Electrical Engineering, vol. 6, no. 10, pp. 2028-2032, 2015.

[9] E. Mhawi, H. Daniyal, and Mohd H. Sulaiman, "Advanced techniques in harmonic suppression via active power filter: A review," International Journal of Power Electronics and Drive System (IJPEDS), vol. 6, no. 2, pp. 185-195, 2015.

[10] L. D. Sahu and S. P. Dubey, "ANN based hybrid active power filter for harmonics elimination with distorted mains," International Journal of Power Electronics and Drive System (IJPEDS), vol. 2, no. 3, pp. 241-248, 2012.

[11] P. Thirumoorthi and Raheni T. D, "Adaptive method for power quality improvement through minimization of harmonics using artificial intelligence," International Journal of Power Electronics and Drive System (IJPEDS), vol. 8, no. 1, pp. 470-482, 2017.

[12] M. H. Alaee, S. A. Taher, and Z. D. Arani, "Improved performance of single-phase shunt active power filter by using conservative power theory and model predictive control," 9th Annual Power Electronics, Drives Systems and Technologies Conference, pp. 163-168, 2018.

[13] D. Joseph, N. Kalaiarasi, and K. Rajan, "A novel reference current generation algorithm for three phase shunt active power filter," Pow. Elec. and Renew. Energy Systems: Proc. of ICPERES, vol. 326, pp. 1467-1475, 2015.

[14] V. Khadkikar and A. Chandra, "Three-phase and single-phase p-q theories applied to three-phase shunt active power filter under different operating conditions: A comparative evaluation," Int. Journal of Emerging Electric Power Systems, vol. 11, no. 2, pp. 1-30, 2010.

[15] D. M. Soomro, et al., "Performance of shunt active power filter based on instantaneous reactive power control theory for single-phase system," Int. Journal of Renewable Energy Research, vol. 7, no. 4, pp. 1741-1451, 2017. 
[16] G. Salunkhe and A. M. Sapkal, "Reduction of harmonics in induction motor drive using harmonic injection method," IEEE International Conference on Recent Trends in Electronics, Information and Communication Technology, pp. 1231-1234, 2016.

[17] H. Oraee and A. E. Emanuel, "Induction motor useful life and power quality," IEEE Power Engineering Review, vol. 20 , no. 1 , pp. $47,2000$.

[18] L. Jing and S. Mekhilef, "DSP based implementation of adaptive speed controller for three-phase induction motor," TENCON 2008 IEEE Region 10 Conference, Hyderabad, pp. 1-5, 2008

[19] Z. Yu, A. Mohammed, and I. Panahi, "A review of three PWM techniques," American Control Conference, Albuquerque, NM, vol. 1, pp. 257-261, 1997.

[20] L. A. Moran, J. W. Dixon, and R. R. Wallas, "A three-phase active power filter operating with fixed switching frequency for reactive power and current harmonic compensation," IEEE Trans. Industrial Elec., vol. 42, no. 4, pp. 402-408, 1995.

[21] D. Janyavula and S. N. Saxena, "Unbalanced variable nonlinear load compensation using multiple shunt active filters," International Journal of Electrical and Computer Engineering (IJECE), vol. 5, no. 5, pp. 896-904, 2015.

[22] H. Akagi, E. H. Watanabe, and M. Aredes, "Instantaneous power theory and applications to power conditioning-2 $2^{\text {nd }}$ edition," IEEE Press, John Wiley \& Sons Inc., 2017.

[23] G. A. Jyothi and P. V. R. L. Narasimham, "Implementation of instantaneous reactive power theory for current harmonic reduction and reactive power compensation in three phase four wire power system," IOSR Journal of Electrical and Electronics Engineering, vol. 10, no. 1, ver. II, pp. 68-74, 2015.

[24] M. Manikandan and R. R. Das, "Analysis and simulation of shunt active power filter under unbalanced and distorted load conditions," Int. J. on Recent Trends in Engineering \& Technology, vol. 05, no. 2, pp. 173-176, 2011.

[25] D. M. Soomro, S. C. Chong, Z. A. Memon, and F. Abbasi, "Power quality improvement in QUCEST Larkana Campus by using three types of power filters," International Journal of Power Electronics and Drive System (IJPEDS), vol. 8, no. 4, pp. 1876-1885, 2017.

\section{BIOGRAPHIES OF AUTHORS}

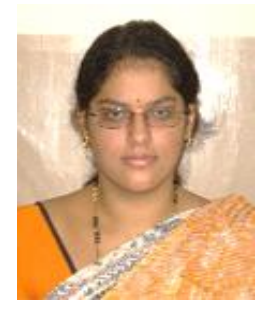

Madhu B. R. is working as faculty in EEE department RVCE, Bengaluru. She received B.E degree in Electrical \& Electronics Engineering from VTU, Belgaum and M.S (ASIC Design) from Mangalore University. Her research interests are HVDC converters, Power Electronics, Control Systems, Logic Design, ASIC Design. She is pursuing PhD in Active Filters under Jain University, Bengaluru. E-mail: madhubr@rvce.edu.com

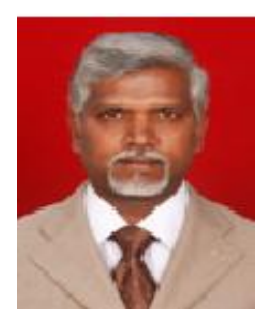

M. N. Dinesh, born in Karnataka, India in 1965. He received his electrical engineering degree from Bangalore University during 1988, His M.E degree from Bangalore University during 1994 and obtained Ph.D degree from Visvesvaraya Technological University during 2010. Since 1988 he is in teaching, presently working in the Department of Electrical and Electronics Engineering, RVCollege Engineering, Bangalore 59. E-mail:dineshmn@ rvce.edu.in

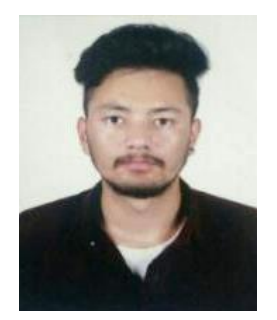

Tsewang Thinlas, born in Leh, Jammu and Kashmir, India in 1995. He is presently pursuing his B.E degree in Electrical and Electronics Engineering (2015-19) at RVCE. His areas of interest are analog electronics, control systems and power systems. Email: tsewangt.ee15@rvce.edu

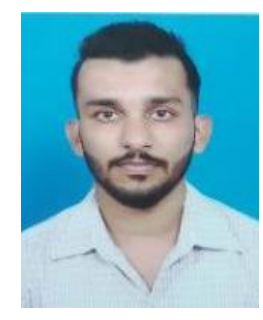

Deril Menezes, born in Karnataka, India in 1995. He received diploma in Electrical and Electronics Engineering from SNM Polytechnic in 2016 and presently pursuing his Engineering at RVCE (2016-19). His areas of interests are Electrical Machines and Power Electronic devices. Email: derilm.ee16@rvce.edu.in 